78

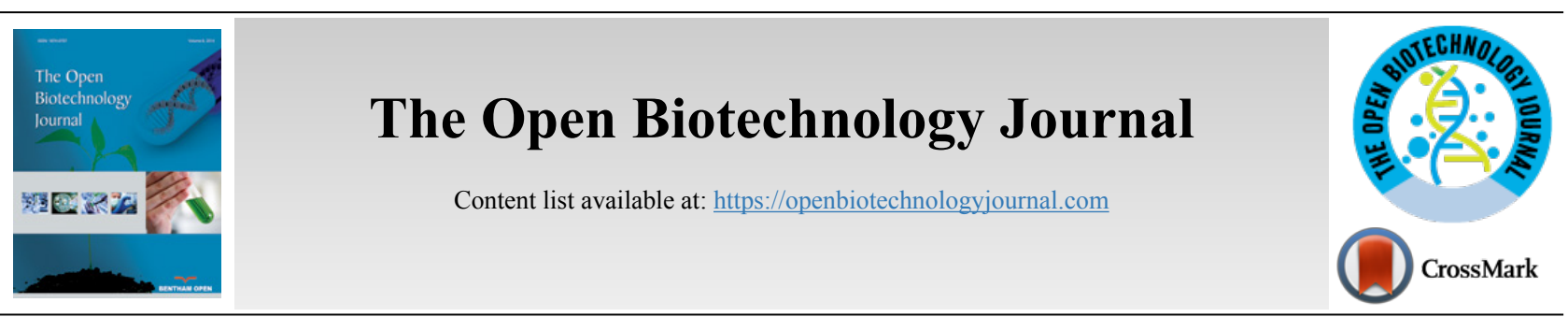

REVIEW ARTICLE

\title{
Tea from the Food Science Perspective: An Overview
}

\author{
Miluska Cisneros-Yupanqui ${ }^{1}$ and Anna Lante ${ }^{1, *}$ \\ ${ }^{l}$ Department of Agronomy, Food, Natural Resources, Animals, and Environment - DAFNAE, University of Padova, Viale Università, Agripolis, Italy
}

Abstract: Tea (Camelia sinensis L.) is one of the main beverages known and consumed all around the world. Quality of tea is not only linked to the raw material but also to the processing steps that influence on the biochemical and sensory characteristics of each type of tea. This overview is focused on the differences in the production and composition of the main types of teas present in the market, highlighting not only their chemical and sensory characteristics, but also the importance of this plant from the food science viewpoint related to its several applications.

Keywords: Green tea, Oolong tea, Black tea, Tea processing, Polyphenol oxidase, Tea polyphenols.

\begin{tabular}{l|l|l|l} 
Article History & Received: December 23, 2019 & Revised: February 28, 2020 & Accepted: May 03, 2020
\end{tabular}

\section{INTRODUCTION}

Tea (Camelia sinensis L.) is a native plant from the East and South Asia considered for medicinal purposes and for consumption as a beverage. The composition of tea is affected by a variety of factors such as cultivation techniques, environmental conditions, tea grades and post-harvest technology. According to the technological process and the level of oxidation, under specific temperature and relative humidity, tea can be classified into three main types: nonfermented (green tea), semi-fermented (oolong tea) and fully fermented (black tea) [1]. The so-called fermentation in some types of tea is the oxidation performed by the enzyme Polyphenol Oxidase (PPO), which catalyzes the oxidation of fresh tea polyphenols, especially catechins, into $o$-quinones, which are polymerized into theaflavins and thearubigins. These compounds appear to be the major products of the preliminary oxidation reactions [2], while the also produced theabrownins may be derived by the non-enzymatic browning reaction (also named as Maillard reaction) [3 - 5].

Nowadays, the use of tea extract can be proposed for controlling PPO activity of food products [6] as well as an antimicrobial agent [7], a natural additive for counteracting the lipid oxidation $[6,8]$, and for inhibiting the non-enzymatic browning [9]. Therefore, the aim of this overview is to describe the impact of tea processing on its quality and composition as well as the recent issues related to this topic. The importance of tea from the food science viewpoint regarding its applications as a natural additive is also mentioned.

* Address correspondence to this author at the Department of Agronomy, Food, Natural Resources, Animals, and Environment - DAFNAE, University of Padova, Anna Lante, Viale Università 16, 35020, Agripolis, Italy; Tel: +39 049 8272920; E-mail: anna.lante@unipd.it

\section{TEA CLASSIFICATION AND CHEMICAL COMPO- SITION}

Tea can be classified mainly as green (non-fermented), oolong (semi-fermented) and black tea (completely fermented), according to the process that is carried out during its processing. All these types of tea come from the same plant, but in order to achieve the main characteristics of each one, the combination or the separation of some specific unit operations as fixation, withering, rolling, fermentation and drying [5, 10 12] are required, as shown in (Table 1).

Table 1. Unitary operations involved in tea processing.

\begin{tabular}{|c|c|}
\hline Unitary Process & Description \\
\hline Fixation & $\begin{array}{c}\text { Carried out by steaming, pan-fired, and sunning. } \\
\text { The aim is to deactivate the endogenous enzymes } \\
\text { presented in the fresh tea leaves }\end{array}$ \\
\hline Withering & $\begin{array}{c}\text { Natural and spontaneous process that allows the } \\
\text { reduction of the moisture content of tea leaves. The } \\
\text { aim of the withering is to improve the flavor in } \\
\text { green, oolong, and black tea }\end{array}$ \\
\hline Rolling & $\begin{array}{c}\text { Performed to obtain the different kinds of shape of } \\
\text { tea leaves }\end{array}$ \\
\hline Fermentation & $\begin{array}{c}\text { It is so-called the enzymatic oxidation catalyzed by } \\
\text { PPO in order to oxidize polyphenols into tannins } \\
\text { and complex quinones }\end{array}$ \\
\hline Drying & $\begin{array}{c}\text { Unitary operation performed in order to stop the } \\
\text { oxidation progress and to reach a moisture level of } \\
3-4 \% \text { (wet basis) to facilitate handling and } \\
\text { transportation }\end{array}$ \\
\hline
\end{tabular}

The composition of tea fresh leaves, mainly water as well as astringent and bitter compounds, is affected by a variety of factors such as crop cultivation, environmental conditions and 
tea grades [13]. Also, the tea composition depends on the kind of variety produced since the technological process is reported to play an important role in this aspect as well as in the sensory attributes (color, taste, aroma), and the nutritional content of tea.

\subsection{Green Tea}

Green tea, representing $20 \%$ of world's tea consumption, is produced after fixation, rolling and drying of tea leaves [5, 14]. The fixation, which is blanching at high temperatures, allows controlling the PPO activity. For this reason, only little fermentation occurs in this kind of tea and its composition is similar to the fresh tea leaves $[11,15]$. During fixation, the tea leaves retain the highest amount of fresh tea polyphenols (catechins, gallic acid, chlorogenic acid, and flavonols). Catechins (flavan-3-ols) are the most important polyphenols in green tea; their proportion is up to $25-35 \%(\mathrm{w} / \mathrm{w})$ of the leaves and are responsible for the bitterness and astringency of tea [1, $16,17]$. In addition, catechins can be divided into free catechins such as Epicatechins (EC), Gallocatechins (GC), and Epigallocatechins (EGC), and into esterified or galloyl catechins such as Epicatechins-3-Gallate (ECG), and Epigallocatechin-3-Gallate (EGCG). This latter represents up to $59 \%$ of the total catechins $[17,18]$. Regarding non-phenolic metabolites, amino acids, sugars and organic acids are part of the composition of green tea; free sugars are responsible for the synthesis of catechins by contributing soluble solids and flavor components during the green tea processing [19]. On the other hand, the carbohydrates present in tea leaves include cellulosic fibers and pectins (up to $33 \%$ dry weight) while linoleic and $\alpha$ linolenic acid are the most abundant fatty acids reported. Some vitamins, pigments, minerals, volatile compounds and carotenoids are trace elements present in green tea leaves, relevant for the aroma development [17].

Furthermore, numerous flavor compounds are present in the fresh tea leaves, as well as the non-protein amino acid Ltheanine (5- $\mathrm{N}$-ethyl-L-glutamine), whose amount is higher in unfermented teas, varying from 1.83 to $9.74 \mathrm{mg} / \mathrm{g}$ from the darkest teas to the fresh leaves, respectively. Due to its umami taste, L-theanine contributes to the fresh taste of the green tea infusion and it represents more than $50 \%$ of the total free amino acids detected in green tea leaves. In addition, the amino acids L-glutamic and L-aspartic acid contribute to the characteristic umami flavor of this kind of tea $[1,5,11]$. Regarding color, a green tea infusion does not contain highly colored products since there is not pronounced oxidation, so the desired color in this kind of tea is greenish or yellowish because of the chlorophyll content. The yellow color is due to the water-soluble flavonols (kaemperferol, quercetine, myrecitin) and flavones (apigenin, isovitexin, saponarin), which represent 1.3 to $1.5 \%$ and $0.02 \%$ of the tea leaves (dry basis), respectively [14].

\subsection{Oolong Tea}

Oolong tea represents $2 \%$ of the world tea consumption and it is a partially fermented (in the range of $10-70 \%$ ) product with a unique flavor attributed to its content of non-oxidized catechins (representing $8.1 \% \mathrm{w} / \mathrm{w}$ ), caffeine, and thearubigins among other compounds. The content of total polymerized polyphenols is $5.1 \%(\mathrm{w} / \mathrm{w})$, which is lower than that contained in black tea [20]. In the manufacture of oolong tea, fresh leaves are withered under the sunlight during a short period with a further withering done indoors for several hours with a gentle rolling, followed by a short fermentation, a heating process, and a quick drying in order to halt the oxidation $[11,14,21$, 22]. It is important to mention that the main factor responsible for the aroma in this kind of tea is the indoor withering, which is, essentially, enzymatic oxidation. Also, the lipids presented in this kind of tea provide aroma through their degradation, such as the compound methyl jasmonate, which is a product derived from the oxidation of $\alpha$-linolenic acid, and it is reported in oolong tea in a range from 0.38 to $0.89 \mu \mathrm{g} / \mathrm{g}$ of tea [23 - 25]. Other oolong tea characteristic aromas are nerolidol, indole, and jasmine lactone. Regarding flavor, it is due to a mixture of different compounds such as catechins, amino acids, soluble sugars, theaflavins, and thearubigins, which give oolong tea bitterness, freshness, sweetness, briskness, and mellowness, respectively [22].

In addition, oolong tea presents higher content of glutamine $(3.46 \mathrm{mg} / \mathrm{g}$ fresh tea leaves) than other types of tea (including the fresh tea leaves), suggesting that the process of oolong tea preparation can contribute to the glutamine accumulation [24]. Theasinensin is another compound found in oolong tea (approximately $2.56 \mathrm{mg} / \mathrm{g}$ dried leaf), and it is relevant because it presents ten times more absorption than EGCG [20, 26].

\subsection{Black Tea}

Black tea, which represents $20 \%$ of the total worldwide consumption [14], is processed without the control of enzymatic browning, which allows the increase of the concentration of theaflavins and thearubigins. The PPO activity is enhanced by using rolling, which causes the damage of surfaces of fresh tea leaves, facilitating the contact of tea polyphenols with the enzyme PPO, leading to full fermentation. The main oxidation products of catechins in black tea are theaflavins, which contribute to the unique black tea flavor and the reddish-orange color. These compounds account for $3 \%$ to $5 \%(\mathrm{w} / \mathrm{w})$ of the black tea solid extract and they represent $50-60 \%$ of the total flavonoids found in this kind of tea $[2,11,20]$. In addition, thearubigins are deep oxidation products (synthetized during the so-called fermentation) of catechins and theaflavins, accounting for about $20 \%(\mathrm{w} / \mathrm{w})$ of total solids of black tea and $10 \%$ of the total flavonoids in black tea $[20,27]$. These compounds increase with the progression of fermentation, which has been recognized as one of the main responsible steps for the sensory quality and chemical composition of black tea [28]. In this regard, depending on the fermentation degree, some green tea polyphenols (especially flavonols) remain in black tea at similar quantities [17]. The recommended ratio between theaflavins and thearubigins in order to obtain a desirable tea quality is $1: 10$. Otherwise, an overfermentation could degrade theaflavins to thearubigins, developing a non-desired thickness [12].

The synthesis of thearubigins has been reported to be favored at high temperatures while a better conversion from 
catechins to theaflavins was observed at a lower temperature [27]. This shows that time and temperature are always critical factors that could affect the transformation and degradation of original compounds, following the Maillard reaction mechanism to reach appearance, aroma, and taste of the final tea and infusion. In this regard, aroma and taste, which consist of volatile and non-volatile compounds respectively, are the main categories of tea flavor [23]. Some compounds related to the black tea flavor are linalool oxide (sweet), geraniol (floral), phenyl acetaldehyde (floral), benzaldehyde (fruity), methyl salicylate (fruity), phenyl ethanol (fruity) and hexanal (grassy). In addition, the compounds aforementioned are responsible for black tea odor [29] while theaflavins, thearubigins, catechins, EGCG, caffeine and amino acids are the ones responsible for black tea taste (rough astringent, ashy, puckering astringent, bitter, creamy and brothy, respectively) $[14,29,30]$.

Furthermore, in the production of oolong and black tea, Ltheanine affects tea aroma through the Maillard reaction, and it is considered besides polyphenols, as the major bioactive secondary metabolite from tea $[3,31]$. It is important to mention that Maillard reaction products from tea, such as furosine and 5-hydroxymethylfurfural have been used to measure the extension of not only the Maillard reaction, but also the heat management; it was pointed out that furosine is a marker of tea processing while 5-hydroxymethylfurfural is an effective marker of storage conditions [32].

On the other hand, it is important to understand the effect of enzyme PPO on the flavor of tea. In fact, the oxidized tea flavanols-quinones are oxidizing reagents of theanine and other free amino acids in tea leaves, so their corresponding Strecker aldehydes are produced during the tea manufacturing process [23]. Moreover, the oxidized tea flavanols-quinones are oxidizing reagents for degradation of carotenoids such as neoxanthin, a key step in the production of $\beta$-damascenone which has an essential odor (fruity, apple-like), especially present in black tea, but also in green and oolong ones [23].

\section{RECENT ADVANCEMENTS IN TEA PROCESSING}

Instant tea was the first alternative to the traditional way of tea preparation and it involved the preparation of the tea infusion, followed by the concentration and drying, either spray or freeze one [21]. Nowadays, there is an increasing demand for Ready-to-Drink (RTD) tea since it is more convenient and practical, especially for young people [11], while instant tea consumption has reduced [21], producing changes in the tea processing. RTD tea is mostly prepared from black and green tea and it is consumed cold. In addition, the inoculation of specific bacterial culture may be possible, so RTD tea could be considered a probiotic beverage if beneficial bacteria are included [17].

Another alternative to commercialized tea is as a concentrated form. It is convenient because it presents a better quality than instant tea; however, the shelf life could be lower. The main concern in this type of preparation is the preservation of bioactive compounds such as polyphenols and catechins. In this sense, the extraction of bioactive compounds from tea has been currently studied. Technologies such as ultra-sonication and agitation extraction have been used in this regard due to increase in the polyphenols, catechins, and flavonoids yield, obtaining a higher antioxidant activity [33].

Tons of industrial waste are discarded during tea processing, even if these tea residues are a relevant source of bioactive compounds. Therefore, the use of tea-waste processing is gaining attention since it presents an interesting composition that can exert a functionality within the food industry $[7,34]$. In fact, tea residues can be used during the processing of instant tea by spray drying, making them an added value instead of a waste [17].

\section{TEA AS INHIBITOR OF ENZYMATIC AND NON- ENZYMATIC BROWNING}

Natural inhibitors of PPO have been recently studied within the food industry as a replacement of synthetic additives in order to enhance the sensory properties of products [35]. In this regard, tea has been used as an inhibitor of PPO in the Pacific white shrimp [6]. Probably, catechins act as a PPO competitive inhibitor since they have a similar structure to PPO substrate, and constitute about $90 \%$ of the total tea phenolic content. In addition, green tea extract has been used to inhibit the activity of PPO by an average of $75 \%$ in cloudy apple juice [36]. On the other hand, Maillard reaction products from apples and eggplants processing have been used as inhibitors of the activity of PPO by chelating the copper ions of the active site of the enzyme. This outcome could be applicable when using tea since it presents Maillard reaction products, too [37].

Regarding non-enzymatic browning, green tea extracts have been used to inhibit the formation of Maillard reaction products related to off-flavors in UHT milk. This effect was explained because of the high conjugation between green tea polyphenols and milk proteins. Nevertheless, the browning was much higher in milk with added green tea extracts because of the polymerization of the EGCG, which occurs along with oxidation, creating brown-colored pigments [9]. In addition, it was reported that tea extracts not only reduce Maillard browning associated with fluorescence and color change during UHT milk processing but also have a high consumer acceptance if low concentrations and low storage temperature $\left(4^{\circ} \mathrm{C}\right)$ are employed [38]. Furthermore, it was reported that catechins, especially EGCG do not allow the formation of Advanced Glycation End-products (AGEs) by inhibiting glyoxal formation from glucose [39].

\section{OTHER TEA APPLICATIONS WITHIN THE FOOD INDUSTRY}

Tea has been used within food science, mainly because of the presence of bioactive compounds. Catechins, especially EGCG, have been studied as a natural antimicrobial since they inhibit the Staphylococcus aureus methicillin-resistant along with $\beta$-lactams [40], and the growth of Escherichia coli and Helicobacter pylori [41, 42]. Catechins exert this antimicrobial effect by reducing the antioxidant capacity of foodborne pathogens and it depends on the dose and time of exposure [42, 43]. Among other applications, catechins can be mentioned for their use in yogurt manufacturing where no effect on yogurt microorganisms and lactic acid level was appreciated after the addition of catechins; however, these metabolites could 
increase the amount of probiotics such as Bifidobacteria, which is mainly used in the yogurt industry [43, 44]. Furthermore, a film based on catechins has been applied to preserve the quality of packed mushrooms, even if the required concentration to appreciate the effect leads to the loss of the mechanical properties [45].

Regarding the use of tea extract as an antioxidant, green tea has shown performance comparable to the one of the most used synthetic antioxidant Tert-butylhydroquinone (TBHQ) [1]. Also, green tea extract has been related to keeping the redness and the umami taste in meat products, even if the mechanism employed has not been clearly defined. Nevertheless, the tastiness intensity of green tea and the umami taste were attributed to a synergy among the content of threonine, aspartic acid, and glutamic acid [1, 19, 46].

In order to increase the low bioavailability of bioactive compounds such as catechins, nanoemulsions from tea extract have been developed [47]. It is important to mention the large interface present in emulsions, and the complex food matrix which increases the susceptibility to lipid oxidation $[1,48]$. In this regard, green tea nanoemulsions (W/O) were used as natural antioxidants in order to prevent rancidity and to bring functional properties to many types of oil. A green tea/peanut oil emulsion presents the highest oxidative stability in comparison to soy, sunflower and corn oils [8]. In shrimps, green tea extracts have been responsible for decreasing the TBARS values, retarding the lipid oxidation. This was attributed to the radical-scavenging activity and to the capacity of chelating metals that tea has, slowing the propagation stage and preventing rancidity in vulnerable samples [6]. Furthermore, another important application of tea polyphenols nanoemulsions was the improvement of the absorption, stability, and retention of $\beta$-carotene [49]. Green tea extract has been used in the development of an active film in spite of improving the meat shelf life by controlling its lipid oxidation [50].

Likewise, tea powder, soluble tea and tea polyphenols were used to increase the dough strength of noodles, being the tea polyphenols not only the most effective dough stabilizer but also the best in developing a better gluten network by improving the $\alpha$-structures and hydrophobic interactions [51]. However, the scale-up of tea polyphenols application needs to tackle not only the low bioavailability, improving the polyphenols absorption, but also the potential toxicity present in the polyphenols of tea [5]. Regarding toxicity, it was reported that the administration of green tea at an in vivo level did not present adverse effects when $2500 \mathrm{mg} / \mathrm{kg}$ body weight/day was used [52]. Also, a lipid-soluble green tea extract showed no significant effects on hematology, clinical chemistry, among other parameters, supporting the safety of tea extracts [53].

\section{CONCLUSION}

The different chemical composition and unitary operations carried out in each type of tea make them unique from the food science point of view, not only for the different sensory properties they acquire but also for the biochemistry implied within the manufacturing. The difference among teas leads to many applications, which are being considered with more interest by the food industry to use this plant as a powerful ingredient.

\section{LIST OF ABBREVIATIONS}

$\begin{array}{ll}\text { PPO } & =\text { Polyphenol Oxidase } \\ \text { EC } & =\text { Epicatechins } \\ \text { GC } & =\text { Gallocatechins } \\ \text { EGC } & =\text { Epigallocatechins } \\ \text { EGCG } & =\text { Epigallocatechin Gallate } \\ \text { TBHQ } & =\text { Tert-butylhydroquinone } \\ \text { AGEs } & =\text { Advanced Glycation End-products }\end{array}$

\section{CONSENT FOR PUBLICATION}

Not applicable.

\section{FUNDING}

The study was financially supported by the University of Padova. DOR1853907/18.

\section{CONFLICT OF INTEREST}

The authors declare no conflict of interest, financial or otherwise.

\section{ACKNOWLEDGEMENTS}

We would like to thank prof. Stefano Schiavon, coordinator of the Animal and Food Science Ph.D course and Mrs Rosalba Moro for their continued support.

\section{REFERENCES}

[1] Namal Senanayake SPJ. Green tea extract: Chemistry, antioxidant properties and food applications - A review. J Funct Foods 2013; 5: 1529-41.

[http://dx.doi.org/10.1016/j.jff.2013.08.011]

[2] Teng J, Gong Z, Deng Y, et al. Purification, characterization and enzymatic synthesis of theaflavins of polyphenol oxidase isozymes from tea leaf (Camellia sinensis). Lebensm Wiss Technol 2017. [http://dx.doi.org/10.1016/j.lwt.2017.05.065]

[3] Benjamin Caballero PMF and FT Encyclopedia of Food and Health. n.d.

[4] Zhou H, Li HM, Du YM, et al. C-geranylated flavanones from YingDe black tea and their antioxidant and $\alpha$-glucosidase inhibition activities. Food Chem 2017; 235: 227-33.

[http://dx.doi.org/10.1016/j.foodchem.2017.05.034]

[PMID: 28554631]

[5] Zhang L, Ho C, Zhou J, Santos JS, Armstrong L, Granato D. Chemistry and biological activities of processed Camellia sinensis teas: A comprehensive review. Compr Rev Food Sci Food Saf 2019; 18: 1474-95.

[http://dx.doi.org/10.1111/1541-4337.12479]

[6] Nirmal NP, Benjakul S. Use of tea extracts for inhibition of polyphenoloxidase and retardation of quality loss of Pacific white shrimp during iced storage. Lebensm Wiss Technol 2011; 44: 924-32. [http://dx.doi.org/10.1016/j.lwt.2010.12.007]

[7] Zhang H, Chen L, Yang T, et al. Production of superfine green tea powder from processing wastes: Characterization of chemical composition and exploration of antimicrobial potential against Ralstonia solanacearum. LWT 2019; 104: 142-7.

[http://dx.doi.org/10.1016/j.lwt.2019.01.032]

[8] Lante A, Friso D. Oxidative stability and rheological properties of nanoemulsions with ultrasonic extracted green tea infusion. Food Res Int 2013; 54: 269-76.

[http://dx.doi.org/10.1016/j.foodres.2013.07.009]

[9] Jansson T, Waehrens SS, Rauh V, et al. Effect of green tea catechins 
on physical stability and sensory quality of lactose-reduced UHT milk during storage for one year. Int Dairy J 2019; 95: 25-34

[http://dx.doi.org/10.1016/j.idairyj.2019.03.007]

[10] Wang Y, Zheng PC, Liu PP, et al. Novel insight into the role of withering process in characteristic flavor formation of teas using transcriptome analysis and metabolite profiling. Food Chem 2019; 272: 313-22.

[http://dx.doi.org/10.1016/j.foodchem.2018.08.013] [PMID: 30309549]

[11] Yu P, Yeo ASL, Low MY, Zhou W. Identifying key non-volatile compounds in ready-to-drink green tea and their impact on taste profile. Food Chem 2014; 155: 9-16.

[http://dx.doi.org/10.1016/j.foodchem.2014.01.046] [PMID: 24594147]

[12] Jolvis Pou KR, Paul SK, Malakar S. Industrial processing of ctc black tea Caffeinated and cocoa based beverages. Elsevier 2019; pp. 131-62. [http://dx.doi.org/10.1016/B978-0-12-815864-7.00004-0]

[13] Chen Q, Zhu Y, Dai W, et al. Aroma formation and dynamic changes during white tea processing. Food Chem 2019; 274: 915-24.

[http://dx.doi.org/10.1016/j.foodchem.2018.09.072]

[PMID: 30373028]

[14] Chaturvedula VSP, Prakash I. The aroma, taste, color and bioactive constituents of tea. J Med Plants Res 2011; 5: 2110-24.

[15] Wang L, Xu R, Hu B, et al. Analysis of free amino acids in Chinese teas and flower of tea plant by high performance liquid chromatography combined with solid-phase extraction. Food Chem 2010; 123: 1259-66.

[http://dx.doi.org/10.1016/j.foodchem.2010.05.063]

[16] Narukawa M, Kimata H, Noga C, Watanabe T. Taste characterisation of green tea catechins. Int J Food Sci Technol 2010; 45: 1579-85. [http://dx.doi.org/10.1111/j.1365-2621.2010.02304.x]

[17] Dubey KK, Janve M, Ray A, Singhal RS. Ready-to-drink tea. Elsevier Inc. 2020.

[http://dx.doi.org/10.1016/B978-0-12-816938-4.00004-5]

[18] Meterc D, Petermann M, Weidner E. Drying of aqueous green tea extracts using a supercritical fluid spray process. J Supercrit Fluids 2008; 45: 253-9.

[http://dx.doi.org/10.1016/j.supflu.2008.02.001]

[19] Das PR, Kim Y, Hong SJ, Eun JB. Profiling of volatile and nonphenolic metabolites-amino acids, organic acids, and sugars of green tea extracts obtained by different extraction techniques. Food Chem 2019; 296: 69-77.

[http://dx.doi.org/10.1016/j.foodchem.2019.05.194]

[PMID: 31202308]

[20] Zhang H, Qi R, Mine Y. The impact of oolong and black tea polyphenols on human health. Food Biosci 2019; 29: 55-61. [http://dx.doi.org/10.1016/j.fbio.2019.03.009]

[21] Heck CI, Gonzalez de Mejia E. Teas and tea-based functional beverages. Woodhead Publishing Limited 2009.

[http://dx.doi.org/10.1533/9781845695569.3.396]

[22] Chen YL, Duan J, Jiang YM, Shi J. Production, quality, and biological effects of oolong tea (Camellia sinensis). Food Rev Int 2010; 27: 1-15. [http://dx.doi.org/10.1080/87559129.2010.518294]

[23] Ho C-T, Zheng X, Li S. Tea aroma formation. Food Sci Hum Wellness 2015; 4: 9-27.

[http://dx.doi.org/10.1016/j.fshw.2015.04.001]

[24] Jiang H, Yu F, Qin L, et al. Dynamic change in amino acids, catechins, alkaloids, and gallic acid in six types of tea processed from the same batch of fresh tea (Camellia sinensis L.) leaves. J Food Compos Anal 2019; 77: 28-38.

[http://dx.doi.org/10.1016/j.jfca.2019.01.005]

[25] Wang D, Kubota K, Kobayashi A. Optical isomers of methyl jasmonate in tea aroma. Biosci Biotechnol Biochem 1996; 60(3): 508-10.

[http://dx.doi.org/10.1271/bbb.60.508] [PMID: 27299556]

[26] Shii T, Tanaka T, Watarumi S, et al. Polyphenol composition of a functional fermented tea obtained by tea-rolling processing of green tea and loquat leaves. J Agric Food Chem 2011; 59(13): 7253-60. [http://dx.doi.org/10.1021/jf201499n] [PMID: 21627083]

[27] Samanta T, Cheeni V, Das S, Roy AB, Ghosh BC, Mitra A. Assessing biochemical changes during standardization of fermentation time and temperature for manufacturing quality black tea. J Food Sci Technol 2015; 52(4): 2387-93.

[http://dx.doi.org/10.1007/s13197-013-1230-5] [PMID: 25825546]

[28] Qu F, Zhu X, Ai Z, Ai Y, Qiu F, Ni D. Effect of different drying methods on the sensory quality and chemical components of black tea. LWT 2019; 99: 112-8. [http://dx.doi.org/10.1016/j.lwt.2018.09.036]

[29] Jolvis Pou KR. Fermentation: The key step in the processing of black tea. J Biosyst Eng 2016; 41: 85-92.

[http://dx.doi.org/10.5307/JBE.2016.41.2.085]

[30] Sharma V, Rao LJM. A thought on the biological activities of black tea. Crit Rev Food Sci Nutr 2009; 49(5): 379-404. [http://dx.doi.org/10.1080/10408390802068066] [PMID: 19399668]

[31] Sanlier N, Gokcen BB, Altuğ M. Tea consumption and disease correlations. Trends Food Sci Technol 2018; 78: 95-106. [http://dx.doi.org/10.1016/j.tifs.2018.05.026]

[32] Pérez-Burillo S, Jiménez-Zamora A, Párraga J, Rufián-Henares JA, Pastoriza S. Furosine and 5-hydroxymethylfurfural as chemical markers of tea processing and storage. Food Control 2019; 99: 73-8. [http://dx.doi.org/10.1016/j.foodcont.2018.12.029]

[33] Das PR, Eun JB. A comparative study of ultra-sonication and agitation extraction techniques on bioactive metabolites of green tea extract. Food Chem 2018; 253: 22-9.

[http://dx.doi.org/10.1016/j.foodchem.2018.01.080]

[PMID: 29502824]

[34] Xingfei L, Shunshun P, Wenji Z, et al. Properties of ACE inhibitory peptide prepared from protein in green tea residue and evaluation of its anti-hypertensive activity. Process Biochem 2020.

[http://dx.doi.org/10.1016/j.procbio.2020.01.021]

[35] Tinello F, Lante A. Recent advances in controlling polyphenol oxidase activity of fruit and vegetable products. Innov Food Sci Emerg Technol 2018; 50: 73-83.

[http://dx.doi.org/10.1016/j.ifset.2018.10.008]

[36] Klimczak I, Gliszczyńska-Świgło A. Green tea extract as an antibrowning agent for cloudy apple juice. J Sci Food Agric 2017; 97(5): 1420-6.

[http://dx.doi.org/10.1002/jsfa.7880] [PMID: 27378649]

[37] Billaud C, Maraschin C, Chow YN, Chériot S, Peyrat-Maillard MN Nicolas J. Maillard reaction products as "natural antibrowning" agents in fruit and vegetable technology. Mol Nutr Food Res 2005; 49(7): 656-62.

[http://dx.doi.org/10.1002/mnfr.200400101] [PMID: 15830337]

[38] Schamberger GP, Labuza TP. Effect of green tea flavonoids on Maillard browning in UHT milk. Lebensm Wiss Technol 2007; 40: 1410-7.

[http://dx.doi.org/10.1016/j.lwt.2006.09.009]

[39] Song DU, Jung YD, Chay KO, et al. Effect of drinking green tea on age-associated accumulation of Maillard-type fluorescence and carbonyl groups in rat aortic and skin collagen. Arch Biochem Biophys 2002; 397(2): 424-9.

[http://dx.doi.org/10.1006/abbi.2001.2695] [PMID: 11795903]

[40] Shimamura T, Zhao W-H, Hu Z-Q. Mechanism of action and potential for use of tea catechin as an antiinfective agent. Antiinfect Agents Med Chem 2007; 6: 57-62.

[http://dx.doi.org/10.2174/187152107779314124]

[41] Díaz-Gómez R, López-Solís R, Obreque-Slier E, Toledo-Araya H Comparative antibacterial effect of gallic acid and catechin against Helicobacter pylori. Lebensm Wiss Technol 2013; 54: 331-5.

[http://dx.doi.org/10.1016/j.lwt.2013.07.012]

[42] Díaz-Gómez R, Toledo-Araya H, López-Solís R, Obreque-Slier E. Combined effect of gallic acid and catechin against Escherichia coli. Lebensm Wiss Technol 2014; 59: 896-900. [http://dx.doi.org/10.1016/j.lwt.2014.06.049]

[43] Ma Y, Ding S, Fei Y, Liu G, Jang H, Fang J. Antimicrobial activity of anthocyanins and catechins against foodborne pathogens Escherichia coli and Salmonella. Food Control 2019; 106106712

[http://dx.doi.org/10.1016/j.foodcont.2019.106712]

[44] Jaziri I, Ben Slama M, Mhadhbi H, Urdaci MC, Hamdi M. Effect of green and black teas (Camellia sinensis L.) on the characteristic microflora of yogurt during fermentation and refrigerated storage. Food Chem 2009; 112: 614-20.

[http://dx.doi.org/10.1016/j.foodchem.2008.06.017]

[45] Wrona M, Bentayeb K, Nerín C. A novel active packaging for extending the shelf-life of fresh mushrooms (Agaricus bisporus). Food Control 2015; 54: 200-7.

[http://dx.doi.org/10.1016/j.foodcont.2015.02.008]

[46] Moawad RK, Abozeid WM, Nadir AS. Effect of nitrite level and tea catechins on residual nitrite and quality indices of raw-cured sausages. J Appl Sci Res 2012; 8: 815-22.

[47] Peng Y, Meng Q, Zhou J, et al. Nanoemulsion delivery system of tea polyphenols enhanced the bioavailability of catechins in rats. Food Chem 2018; 242: 527-32.

[http://dx.doi.org/10.1016/j.foodchem.2017.09.094]

[PMID: 
29037724]

[48] Iqbal S, Hameed G, Baloch MK, McClements DJ. Formation of semisolid lipid phases by aggregation of protein microspheres in water-inoil emulsions. Food Res Int 2012; 48: 544-50.

[http://dx.doi.org/10.1016/j.foodres.2012.04.020]

[49] Meng Q, Long P, Zhou J, et al. Improved absorption of $\beta$-carotene by encapsulation in an oil-in-water nanoemulsion containing tea polyphenols in the aqueous phase. Food Res Int 2019; 116: 731-6. [http://dx.doi.org/10.1016/j.foodres.2018.09.004] [PMID: 30717002]

[50] Borzi F, Torrieri E, Wrona M, Nerín C. Polyamide modified with green tea extract for fresh minced meat active packaging applications. Food Chem 2019; 300125242

[http://dx.doi.org/10.1016/j.foodchem.2019.125242] [PMID: 31352285]
[51] Han CW, Ma M, Zhang HH, Li M, Sun QJ. Progressive study of the effect of superfine green tea, soluble tea, and tea polyphenols on the physico-chemical and structural properties of wheat gluten in noodle system. Food Chem 2020; 308125676

[http://dx.doi.org/10.1016/j.foodchem.2019.125676]

[PMID: 31655476

[52] Hsu YW, Tsai CF, Chen WK, Huang CF, Yen CC. A subacute toxicity evaluation of green tea (Camellia sinensis) extract in mice. Food Chem Toxicol 2011; 49(10): 2624-30.

[http://dx.doi.org/10.1016/j.fct.2011.07.007] [PMID: 21771628]

[53] Liu Z, Liu D, Cheng J, et al. Lipid-soluble green tea extract: Genotoxicity and subchronic toxicity studies. Regul Toxicol Pharmacol 2017; 86: 366-73.

[http://dx.doi.org/10.1016/j.yrtph.2017.04.004] [PMID: 28389326]

(C) 2020 Cisneros-Yupanqui and Lante.

This is an open access article distributed under the terms of the Creative Commons Attribution 4.0 International Public License (CC-BY 4.0), a copy of which is available at: (https://creativecommons.org/licenses/by/4.0/legalcode). This license permits unrestricted use, distribution, and reproduction in any medium, provided the original author and source are credited. 